
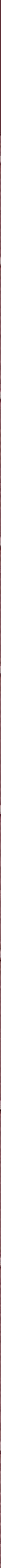



\section{Revista Jurídica}

\section{Universidad Autónoma de Madrid}

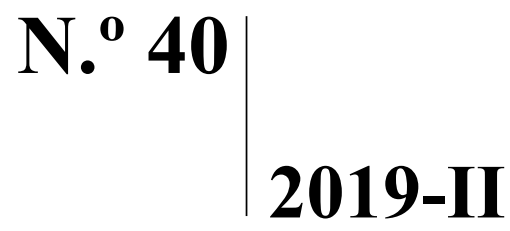

Director: D. Gonzalo Javier Basso (Derecho penal - UAM)

Subdirector: D. Carlos Fernández Esquer (Ciencia política - UAM). Ángela Pilar Fernández Rodríguez (Derecho procesal - UAM). Secretaria académica: Dña. Marta Pantaleón Díaz (Derecho penal - UAM). Dña. Gemma Minero Alejandre (Derecho civil - UAM). Secretario económico: D. Fernando De los Santos Menéndez (Filosofía del Derecho - UAM)

Responsable de difusión y medios digitales: D. Antonio Ismael Ruiz Arranz (Derecho civil - UAM)

\section{Consejo de redacción:}

D. Javier Antón Merino (Ciencia política - Universidad de Burgos)

Dña. Mar Antonino de la Cámara (Derecho Constitucional - UAM)

D. Gonzalo Javier Basso (Derecho penal - UAM)

D. David Casassas Marqués (Filosofia del Derecho - Universitat Autònoma de Barcelona)

D. Jorge Castillo Abella (Derecho administrativo - UAM)

Dña. María Camila Correa Flórez (Derecho penal - Universidad del Rosario).

D. Fernando De los Santos Menéndez (Filosofía del Derecho - UAM)

D. Diego Díez Palacios (Derecho romano - UAM).

Dña. Ester Farnós Amorós (Derecho civil - Universitat Pompeu Fabra)

Dña. Ángela Pilar Fernández Rodríguez (Derecho procesal - UAM)

D. David Gallego Arribas (Derecho penal - UAM)

Dña. María García Casas (Derecho internacional público - UAM)

D. José Antonio García Sáez (Filosofía del Derecho - Universitat de València)

D. Héctor Iglesias Sevillano (Derecho administrativo - UAM)

Dña. Rut Lopera Viñé (Derecho penal - UAM)

D. Antonio Manuel Luque Reina (Historia del Derecho - UAM)

Dña. Mariona Llobet Anglí (Derecho penal - Universitat Pompeu Fabra)

D. Jose María Martín Faba (Derecho civil - UAM)

Dña. Vanessa Menéndez Montero (Derecho internacional público - UAM)

D. Aitor Navarro Ibarrola (Derecho financiero y tributario - Universidad Carlos III de Madrid)

Dña Verónica Nevado Catalán (Derecho civil - UAM)

Dña. Marta Pantaleón Prieto (Derecho penal - UAM)

Dña. Alexia Pato (Derecho internacional privado - Universität Bonn)

D. Daniel Pérez Fernández (Ciencia política - UAM).

D. Leopoldo Puente Rodríguez (Derecho penal - UAM)

D. Antonio Ismael Ruiz Arranz (Derecho civil - UAM)

D. Salvador Ruiz Pino (Derecho romano - Universidad Pontificia de Comillas)

D. Víctor Sánchez del Olmo (Derecho del trabajo y de la seguridad social - Universidad Carlos III de Madrid)

Dña. Isué Natalia Vargas Brand (Derecho civil - UAM)

Consejo asesor:

D. Juan Damián Moreno (Decano de la Facultad de Derecho - UAM)

Dña. Elena García Guitián (Directora del Departamento de Ciencia Política y Relaciones Internacionales - UAM)

Dña. Pilar Pérez Álvarez (Directora del Departamento de Derecho Privado, Social y Económico - UAM)

Dña. Cristina Izquierdo Sans (Directora del Departamento de Derecho Público y Filosofía Jurídica - UAM)

D. Carlos Espósito Massici (Catedrático de Derecho Internacional Público - UAM)

D. Antonio Fernández de Buján (Catedrático de Derecho Romano - UAM)

D. José Luis Guerrero Becar (Profesor de la Escuela de Derecho de la Pontificia Universidad Católica de Valparaíso y Presidente de la Asociación Iberoamericana de Facultades y Escuelas de Derecho Sui Iuris

\section{Dykinson}

ISSN: 1575-720-X 
La Revista Jurídica de la Universidad Autónoma de Madrid fue creada en 1999 con el fin de fomentar la discusión científica en la comunidad académica de los ámbitos del Derecho y la Ciencia Política y de la Administración. En ella se publican, con una periodicidad semestral, artículos, comentarios de jurisprudencia y recensiones relativos a estas áreas de investigación. La Revista Jurídica de la Universidad Autónoma de Madrid se encuentra indexada en las bases de datos científicas más relevantes. Actualmente, es una de las publicaciones jurídicas y politológicas con vocación generalista de mayor impacto en España.

Asimismo, entre las diversas actividades que lleva a cabo para la difusión y promoción de la investigación, la Revista Jurídica de la Universidad Autónoma de Madrid organiza anualmente unas Jornadas sobre temas de actualidad, así como un Premio para Jóvenes Investigadores, con el fin de fomentar el acercamiento de los estudiantes a la investigación científica y a la presentación de ponencias en congresos científicos.

Con el fin de ayudar a un mayor intercambio global de conocimiento, la RJUAM ofrece un acceso libre y abierto a su contenido transcurrido un año a partir de la publicación del número en formato impreso. Puede encontrarse más información sobre la RJUAM en el Portal de Revistas Electrónicas de la Universidad Autónoma de Madrid (www.revistas.uam.es).

Colaboran:

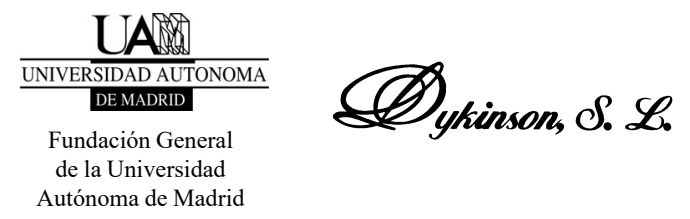

Portada: Marta Conde Diéguez

Logotipo: Marta Conde Diéguez

(C) RJUAM, Madrid

Facultad de Derecho. Ciudad Universitaria de Cantoblanco. 28049 Madrid.

e-mail: revista.juridica@uam.es

http://www.uam.es/rjuam

Editorial DYKINSON, S.L. Meléndez Valdés, 61 - 28015 Madrid.

Teléfono (+34) $915442846-(+34) 915442869$

e-mail: info@dykinson.com

http://www.dykinson.es http://www.dykinson.com

ISSN: 1575-720-X

Depósito Legal: M-39772-1999

Maquetación: german.balaguer@gmail.com

La RJUAM no se hace responsable de las opiniones vertidas por los autores de los trabajos publicados. 


\section{Revista Jurídica de la Universidad Autónoma de Madrid}

Índice n. ${ }^{\circ} 40$ (2019-II)

https://doi.org/10.15366/rjuam2020.40

\section{PRESENTACIÓN}

\section{ARTÍCULOS}

Ramón SANZ FUENTE «Israel como Estado judío y democrático: el régimen político israelí a examen»

Jaume HERNÁNDEZ HERNÁNDEZ «El test de resistencia de los acuerdos impugnables: límites en su aplicabilidad»

Fernando SOLANA ROMERO «China y la dimensión internacional del trabajo: una visión materialista de las relaciones internacionales»

Riccardo GERMANO «Consideraciones generales sobre la responsabilidad penal por la no evitación imprudente del delito doloso ajeno: dos "residuos"»

Cármen MARTÍNEZ FERNÁNDEZ «Censura tardía de la inquisición española a François le Douaren» 



\title{
CONSIDERACIONES GENERALES SOBRE LA RESPONSABILIDAD PENAL POR LA NO EVITACIÓN IMPRUDENTE DEL DELITO DOLOSO AJENO: DOS «RESIDUOS»*
}

\author{
GENERAL CONSIDERATIONS ON THE CRIMINAL LIABILITY FOR \\ NEGLIGENTLY NOT PREVENTING OTHERS FROM COMMITTING \\ INTENTIONAL CRIMINAL OFFENCES: TWO «RESIDUES»
}

\section{RICCARDO GERMANO**}

\begin{abstract}
Resumen: Partiendo de la base de que la responsabilidad penal por no evitar un delito doloso cometido por otra persona nace como reacción a los problemas probatorios por hechos cometidos en estructuras organizativas, se analiza, en primer lugar, las críticas, en relación con este tipo de responsabilidad, de la cláusula general que regula la comisión por omisión en el Código Penal español (art. 11). En segundo lugar, el trabajo aborda dos tipos de comisión por omisión culposas, los cuales, producto de la norma sobre comisión por omisión (art. 11), las normas sobre intervención delictiva (arts. 28 y 29) y el sistema numerus clausus de la culpa (art. 12), no resultan punibles. Finalmente, se analizan las consecuencias colaterales de la criminalización del omitente, incluso si es imprudente: la posible pérdida de un testigo de cargo en relación con el delito no evitado cometido por otra persona y la restricción del principio de la autorresponsabilidad, de manera especialmente grave en los casos de «omisión de protección».
\end{abstract}

Palabras clave: Comisión por omisión; garante imprudente; testimonio.

Abstract: The article takes as a point of departure the fact that the criminal liability for not preventing others from committing intentional criminal offenses can be explained as a reaction to the evidentiary difficulties raised by crimes committed within organized structures. From that standpoint, some critical concerns raised in relation to the general clause regulating liability for omissions in the Spanish Penal Code (art. 11) are firstly analyzed. Secondly, the paper examines two forms of negligent omissions that, as a result of the aforementioned general clause (art. 11), the rules regulating principal and accessory participation in crimes (arts. 28 and 29) and the exceptional criminalization of negligent behavior (art. 12), turn out not to be punishable. Finally, the collateral consequences of the criminalization of (even negligent) omissions in this field are

* https://doi.org/10.15366/rjuam2020.40.004

Fecha de recepción: 20 de octubre de 2019

Fecha de aceptación: 20 de noviembre de 2019

** Doctorando en Derecho penal, Università degli Studi di Milano-Bicocca. El presente trabajo se ha desarrollado en el marco de una estancia de investigación en el Área de Derecho Penal de la Facultad de Derecho de la Universidad Autónoma de Madrid, a cuyos miembros -y en especial a mi tutor, Juan Antonio Lascuraín Sánchez- agradezco mucho su acogida y el estímulo intelectual en la preparación del artículo. Los errores que pueda haber en el texto son solo imputables a mi. 
analyzed: the possible loss of a witness for the prosecution in relation to the offense committed by another person and the restriction of the principle of self-responsibility, especially serious in «failure to protect» cases.

Key words: General clause; negligent omission; witness.

SUMARIO: I. INTRODUCCIÓN AL PROBLEMA DE LA RESPONSABILIDAD PENAL POR LA NO EVITACIÓN DEL DELITO DOLOSO AJENO; II. LA INAPTITUD DE LA CLÁUSULA GENERAL DE LA COMISIÓN POR OMISIÓN (ART. 11 CP) PARA REGULAR LA IMPUTACIÓN DEL DELITO DOLOSO AJENO AL OMITENTE; III. SUPUESTOS DE DIFERENCIA DEL TÍTULO DE IMPUTACIÓN SUBJETIVA ENTRE EL GARANTE (IMPRUDENTE) Y EL AUTOR (DOLOSO): DOS «RESIDUOS»; 1. El primer «residuo»: las omisiones imprudentes de garante no equivalentes; 2 . El segundo «residuo»: las omisiones imprudentes de garante no castigadas, por la Ley, a título de imprudencia; IV. CONSECUENCIAS RELACIONADAS CON LA POLÍTICA CRIMINAL: LA PÉRDIDA DEL TESTIMONIO Y LA REDUCCIÓN DEL PRINCIPIO DE LA AUTORRESPONSABILIDAD; V. BIBLIOGRAFÍA.

\section{INTRODUCCIÓN AL PROBLEMA DE LA RESPONSABILIDAD PENAL POR LA NO EVITACIÓN DEL DELITO DOLOSO AJENO}

En el vasto mundo de la omisión penal existe una hipótesis particular: la responsabilidad omisiva por el delito doloso ajeno es un peculiar fenómeno normativo de duplicación de la responsabilidad penal. No se trata de responsabilidad por no haber impedido un simple hecho naturalístico, tampoco de una autoría mediata, ambas responsabilidades generalmente monosubjetivas ${ }^{1}$, sino de responsabilidad por no haber impedido un delito que, por sí mismo, podría ser autónomamente castigado sin sancionar al omitente. De hecho, después de la omisión castigada por sí misma (omisión propia) y la omisión a la que se imputa un resultado naturalístico ${ }^{2}$, hay una omisión a la que se imputa el delito (doloso) ajeno, es decir un resultado en sentido jurídico ${ }^{3}$ producido por un tercero autorresponsable . $^{4}$

\footnotetext{
1 De hecho, hay casos de autoría mediata (art. 28.1 CP) en la que la responsabilidad penal no es monosubjetiva porque podría castigarse al autor inmediato o instrumento: por ejemplo, la autoría mediata por dominio de un error vencible.

2 Sobre el problema de la asignación de un resultado a una omisión, en virtud de una «competencia de organización» y no por razón de solidaridad (como, en cambio, ocurre con las omisiones propias): JAKOBS, G., «La imputación penal de la acción y de la omisión», $A D P C P$, vol. III, 1996, pp. 839 y ss.; en el mismo sentido, LASCURAÍN SÁNCHEZ, J. A., Los delitos de omisión: fundamento de los deberes de garantía, $1 .^{\mathrm{a}}$ ed., Madrid (Civitas), 2002, pp. 18 y ss.

3 En este sentido, vid. en la doctrina italiana, BISORI, L., «L'omesso impedimento di reato altrui nella dottrina e giurisprudenza italiane», Rivista Italiana di Diritto e Procedura Penale, 1997, pp. 1339 y ss.

4 Remarca este aspecto, en su análisis: ROBLES PLANAS, R., Garantes y cómplices. La intervención por omisión y en los delitos especiales, $1^{\text {a }}$ ed., Barcelona (Atelier), 2007, pp. 61 y ss. Más en general, cfr. también
} 
Tradicionalmente se ha sostenido que la creciente criminalización de las omisiones se relaciona con el desarrollo de la «sociedad del riesgo ${ }^{5}$ ». Sin embargo, si se considera que este específico tipo de responsabilidad penal ha proliferado principalmente en contextos de estructuras organizadas complejas, como las empresas o las fuerzas militares, pareciera ser que existe alguna razón adicional ${ }^{6}$. Si, de hecho, se investiga más allá de la razón formal de política criminal de responsabilizar los centros de elección en las estructuras organizadas, generalmente se encuentra frente a dos problemas procesales: primero, la dificultad probatoria en identificar los autores materiales de los delitos; segundo, la dificultad probatoria en demostrar que el superior ha dado la orden ${ }^{7}$.

Y, por ejemplo, es así que Bacigalupo confiesa, en el prólogo a la segunda edición de Delitos impropios de omisión, como nació su interés por el tema: «[...] tuve que enfrentarme con el problema de la imposibilidad de probar que el Gral. Fonseca había dado la orden de intervenir y era, por lo tanto, probablemente autor mediato de las lesiones de mi patrocinado. En consecuencia, teniendo en cuenta que varios periódicos habían informado de la presencia del General en el lugar del hecho, la querella se orientó como un delito de lesiones cometido por omisión $»^{8}$.

Como premisa del diagnóstico, cabe explicitar el concepto de omisión que se va a utilizar: un concepto rigurosamente normativo ${ }^{9}$. Omisión es la no realización de una prestación positiva exigida, por una norma preceptiva, necesaria para la salvaguarda de un

GIMBERNAT ORDEIG, E., Estudios sobre el delito de omisión, 2a ed., Montevideo (Editorial B de F), 2013, pp. 217 y ss.

5 Vid., por ejemplo, el análisis de GUNTHER, K., «De la vulneración de un derecho a la infracción de deber: ¿un "cambio de paradigma" en el derecho penal?», en La insostenible situación del derecho penal, 1. ${ }^{\mathrm{a}}$ ed., Granada (Editorial Comares), 2000, pp. 500 y ss. Más recientemente, vid. ASHWORTH, A., «A New Generation of Omissions Offences?», The Criminal Law Review, 2018, pp. 357 y ss.

6 Por los hechos ocurridos en América Latina, véase las numerosas referencias en COUSO, J.; WERLE, G., Intervención delictiva en contextos organizados, $1^{\mathrm{a}}$ ed., Valencia (Tirant lo Blanch), 2017. Más en detalle, véase la aplicación de la categoría de la autoría mediata en «aparatos organizados de poder» por parte de Roxin: ROXIN, C., Derecho penal. Parte general. Tomo II. Especiales formas de aparición de delito, $1^{\mathrm{a}}$ ed., Madrid (Civitas), 2014, pp. 111 y ss. Vid. también MUÑOZ CONDE, F., «Eficacias y garantías en la imputación en contextos organizados, a partir del ejemplo de la teoría del dominio del hecho en virtud de aparatos organizados de poder», en Intervención delictiva en contextos organizados, cit., pp. 87 y ss. Acerca de la responsabilidad penal en la empresa, Silva Sánchez afirma que «la estructuras básica de la imputación son entonces la autoría mediata y, sobre todo, la comisión por omisión»: SILVA SÁNCHEZ, J. M., «Criterios de asignación de responsabilidad en estructuras jerárquicas», Cuadernos de derecho judicial, vol. II, 1997, p. 14.

7 Sobre cómo necesidades de prueba llegan a un modelo de Derecho penal y no a otro, vid. IACOVIELLO, F. M., «Processo di parti e prova del dolo», en Criminalia, 2010, pp. 463 y ss.

8 BACIGAlUPO ZAPATER, E., Delitos impropios de omisión, 2. ${ }^{\mathrm{a}}$ ed., Madrid (Dykinson), 2006, p. 2.

9 La omisión «si riferisce a dati che possono essere pensati solo sotto la logica presupposizione di una norma»: ENGISCH, K., «Die normativen Tatbestandselemente im Strafrecht», en Festschrift für Edmund Mezger, 1954, p. 47, cómo traducido por MARINUCCI, G., Il reato come azione. Critica di un dogma, $1^{\text {a }}$ ed., Milano (Giuffrè), 1971, p. 95. En el mismo sentido, por todos: LUZÓN PEÑA, D., Lecciones de derecho penal. Parte general, 3. ${ }^{\mathrm{a}}$ ed., Valencia (Tirant lo Blanch), 2016, pp. 587 y ss. 
bien jurídico ${ }^{10}$. La omisión como «literally nothing at all» ${ }^{11}$ o como concepto naturalístico no interesa, aunque a veces suela impropiamente dársele uso, por ejemplo, en supuestos de participación por (aparente) omisión. De hecho se olvida que, pese a la contraria opinión dominante ${ }^{12}$, en ausencia de un mandato primario de evitar el resultado (deber de garantía), la participación por omisión puede solo ser, si la lógica tiene sentido, la infracción de un mandato menor - por ejemplo, un deber de vigilancia, como lo que tiene el oficial de cumplimiento- en cooperación o complicidad con el delito del tercero ${ }^{13}$. Pero el abandonar una resolución de actuar ya adoptada -como dejar la puerta de casa abierta, cuando generalmente se la cierra ${ }^{14}$ - podrá ciertamente constituir una conducta de participación -en presencia de dolo, o sea del conocimiento de la resolución delictiva, como se dirá ${ }^{15}$ - sin que haga falta llamarla «omisión» ${ }^{16}$ incurriendo en la ambigüedad de utilizar una noción naturalística ${ }^{17}$.

\section{LA INAPTITUD DE LA CLÁUSULA GENERAL DE LA COMISIÓN POR OMISIÓN (ART. 11 CP) PARA REGULAR LA IMPUTACIÓN DEL DELITO DOLOSO AJENO AL OMITENTE}

Intentando ser a-valorativos en grado sumo, o iuspositivistas metodológicos ${ }^{18}$, parecería que el literal posible de la cláusula de la comisión por omisión (art. $11 \mathrm{CP}$ ) constituye

10 Por todos: SILVA SÁNCHEZ, J. M., El delito de omisión. Concepto y sistema, 1. a ed., Barcelona (Librería Bosch), 1986, pp. 123 y ss.; HUERTA TOCILDO, S., Problemas fundamentales de los delitos de omisión, $1^{\mathrm{a}}$ ed., Madrid (Ministerio de Justicia - Centro de Publicaciones), 1987, pp. 281 y ss.

11 MOORE, M., Causation and Responsibility. An essay in Law, Morals, and Metaphysics, 1. ${ }^{\mathrm{a}}$ ed., Oxford (Oxford University Press), 2009, p. 53-129. Contra, FLETCHER, G., Grammatica del diritto penale, 1. ${ }^{a}$ ed., Bologna (Il Mulino), 2004, pp. 79 y ss.

12 La doctrina mayoritaria niega la participación por omisión del sujeto que no es garante; por todos: MIR PUIG, S., Derecho penal. Parte general, 10. ${ }^{\mathrm{a}}$ ed., Barcelona (Reppertor), 2015, p. 425.

13 LASCURAÍN SÁNCHEZ, J. A., «La responsabilidad penal individual en los delitos de empresa», en Derecho penal económico y de la empresa, $1^{\text {a }}$ ed., Madrid (Dykinson), 2018, pp. 101-102. En el sentido de que puede admitirse participación por omisión sin posición de garante, cfr. también: LUZÓN PEÑA, D., Lecciones de derecho penal. Parte general, cit., p. 619; RUEDA MARTíN, M. A., ¿Participación por omisión? Un estudio sobre la cooperación por omisión en un delito de acción doloso cometido por un autor principal, $1^{\text {a }}$ ed., Barcelona (Atelier), 2013, pp. 59 y ss.

14 Ejemplo en ROXIN, C., Autoría y dominio del hecho en derecho penal, $1^{\text {a }}$ ed., Madrid (Marcial Pons), 1998 , pp. 523 y ss.

15 Infra, apartado III.

16 Vid. RISICATO, L., Combinazione e interferenza di forme di manifestazione del reato, Milano (Giuffrè), 2001, pp. 441-443.

17 Así, en cambio, prefieren hablar de «participación por omisión» acerca de estos casos: ROXIN, C., Autoría $y$ dominio del hecho en derecho penal, cit., pp. 523 y ss., si bien específica «lo que considerado fácticamente es un omitir, puede presentarse con arreglo a su sentido social, al margen de todo deber, como hacer favorecedor»; LASCURAÍN SÁNCHEZ, J. A., Los delitos de omisión: fundamento de los deberes de garantía, cit., p. 88.

18 Así BOBBIO, N., El problema del positivismo jurídico, 2. ${ }^{a}$ ed., México (D.F. Fontamara), 1992, pp. 41 y ss.: «El positivismo jurídico está caracterizado por una clara distinción entre derecho real y derecho ideal o, utilizando otras expresiones equivalentes, [...] entre el derecho que es y el derecho que debe ser [...]. Si se quiere usar una sola palabra para designar esta forma de approach al derecho, se la podría llamar "científica" 
un obstáculo para una regulación coherente de la responsabilidad omisiva por el hecho doloso ajeno. A pesar de las diferentes posturas sobre la cuestión ${ }^{19}$, el artículo $11 \mathrm{CP}$ parece ser pensado en función de una responsabilidad monosubjetiva ${ }^{20} \mathrm{y}$ en relación con delitos de resultado (no solo delitos puros de resultado ${ }^{21}$, evidentemente, pero tampoco hasta el punto de incluir, por medio de una interpretatio abrogans, los delitos de mera conducta ${ }^{22}$ ). Por otra parte, la responsabilidad omisiva por el hecho doloso ajeno es plurisubjetiva (o por intervención) y por delitos que no necesariamente son de resultado. Es decir: carece de sentido que un garante no deba impedir delitos de mera actividad-donde el desvalor penal se encuentra en las modalidades de realización-que afectan bienes jurídicos protegidos en el marco de su deber de garantía. Sin embargo el art. $11 \mathrm{CP}$ se refiere-razonablemente, pensando en una responsabilidad monosubjetiva por la no evitación de un resultado en sentido naturalístico, y no jurídico- $\mathrm{a}$ «delitos que consisten en la producción de un resultado».

Es más, la cláusula de comisión por omisión del Código Penal español muestra un quid pluris único por la precisión y el detalle con el que ha sido tipificado: el juicio de equivalencia entre la no evitación y la causación activa del resultado típico; concretización de un debate nacido en Alemania ${ }^{23}$ y desarrollado de manera multiforme en la doctrina española ${ }^{24}$. Si bien este juicio tiene su sentido en relación con una responsabilidad monosubjetiva -representando el refinado producto del debate sobre la subsumibilidad de las conductas omisivas en las normas penales de la parte especial ${ }^{25}$, , carece de sentido cuando se trata de considerar como términos de comparación, por un lado, la omisión del garante

[...]. En esta primera acepción [..], positivista es, por consiguiente, aquel que asume frente al derecho una actitud a-valorativa u objetiva o éticamente neutral; es decir, que acepta como criterio para distinguir una regla jurídica de una no jurídica la derivación de hechos verificables [...] y no la mayor o menor correspondencia con cierto sistema de valores».

19 Resumen las diferentes posturas, por todos: DOPICO GÓMEZ-ALLER, J., Omisión e injerencia en Derecho penal, $2^{\text {a }}$ ed., Valencia (Tirant lo Blanch), 2006, pp. 676 y ss.; PEÑARANDA RAMOS, E., «La tipicidad en los delitos omisivos», en Memento práctico Francis Lefebvre. Penal 2019, 1. a ed., Madrid (Francis Lefebvre), 2018, pp. 180 y ss.

20 Vid. LÓPEZ PEREGRÍN, M. C., La complicidad en el delito, $1^{\text {a }}$ ed., Valencia (Tirant lo Blanch), 1997, p. 334: «el art. $11 \mathrm{Cp}$ parece referirse exclusivamente al autor del delito, al menos en su formulación literal».

${ }^{21}$ Por esta doctrina minoritaria, vid.: BACIGALUPO ZAPATER, E., Derecho penal. Parte general, 2. ${ }^{\text {ed., }}$ Buenos Aires (Hammurabi), 1999, pp. 547, 561; LASCURAÍN SÁNCHEZ, J. A., «Omisiones equivalentes», en Estudios de derecho penal. Homenaje al profesor Santiago Mir Puig, $1^{\text {a }}$ ed., Buenos Aires (Bdef), 2017, pp. 680-681.

22 VIVES ANTÓN, T. S., «Artículo 11. Introducción», en Comentarios al código penal del 1995, 1. a ed., Valencia (Tirant lo Blanch), 1996.

23 Vid., por todos, JESCHECK, H.; WEIGEND, T., Tratado de Derecho Penal. Parte general, 5. a ed., Granada, (Editorial Comares), 2002, pp. 654-657.

24 Viene a colación la síntesis, casi elíptica, propuesta por JORGE BARREIRO, A., «Omisión e imprudencia. Comisión por omisión en la imprudencia: en la construcción y en la medicina en equipo», Cuadernos de derecho judicial. La comisión por omisión - separata, 1994, pp. 232 s., cuando reúne los diferentes asuntos de Schünemann, Gimbernat, Luzon Peña, Silva Sánchez y Gracia Martín bajo «la tesis restrictiva de la comisión por omisión, asumida por un importante sector de la doctrina penal moderna».

25 Por una síntesis, SILVA SÁNCHEZ, J. M., «Apuntes sobre el contexto histórico-dogmático del artículo 11 del código penal», La Ley, núm. 5, 1996, pp. 1557 y ss. 
y, por otro lado, el delito cometido por el tercero autorresponsable ${ }^{26}$, y no solo el resultado naturalístico producido por ese delito: se tendría que negar dicha equivalencia en principio, sobre todo cuando se tratase de equiparar una omisión imprudente a una (conducta activa de intervención en la) acción dolosa de un tercero ${ }^{27}$.

De todas formas, las que parecen lagunas axiológicas han sido ignoradas, quizás razonablemente y pragmáticamente, a través de una «interpretación caritativa» del art. $11 \mathrm{CP}$.

\section{SUPUESTOS DE DIFERENCIA DEL TÍTULO DE IMPUTACIÓN SUBJETIVA ENTRE EL GARANTE (IMPRUDENTE) Y EL AUTOR (DOLOSO): DOS «RESIDUOS»}

El siguiente planteamiento prescindirá, en la medida de lo posible, de los problemas de causalidad (también de la causalidad psíquica, razón por la que escapa de este análisis la hipótesis de la participación omisiva por inducción $)^{28}$ y de imputación objetiva, que no se pueden investigar en esta sede. El que sigue será, en este sentido, un planteamiento ceteris paribus.

Empezando por un dato formal ya mencionado, para el art. 11 del Código penal español no es suficiente la existencia de un deber de garantía -como para la comisión por omisión en el código penal italiano (art. 40.2), inspirada a la teoría formal de las fuentes de los deberes $^{29}$-, sino se requiere también el juicio de equivalencia, «según el sentido del texto de la ley», entre «la no evitación» del resultado y «su causación» (activa). Qué quiere significar esta equivalencia es todavía un misterio ${ }^{30}$-sintetizando, para algunos es una cuestión de subsumibilidad de las modalidades de comportamiento omisivo en los delitos

26 Según MAÑALICH RAFFO, J. P., «Omisión del garante e intervención delictiva. Una reconstrucción desde la teoría de las normas», Revista de Derecho Universidad Católica del Norte, núm. 2, 2014, p. 239, se niega «la equivalencia material entre la ejecución [del abuso sexual], por un lado, y la omisión de una acción consistente en impedir la ejecución de una acción sexual sobre una persona menor de 14 años, por otro».

27 En este sentido, SILVA SÁNCHEZ, J. M., «Aspectos de la comisión por omisión: fundamento y formas de intervención. El ejemplo del funcionario penitenciario», Cuadernos de política criminal, 1989, pp. 380-382.

${ }_{28}$ La doctrina española mayoritaria niega este tipo de responsabilidad; vid., con amplias referencias bibliográficas: GÓMEZ RIVERO, M., La inducción a cometer el delito, $1^{\text {a }}$ ed., Valencia (Tirant lo Blanch), 1995, pp. 212-214; OLMEDO CARDENETE, M., La inducción como forma de participación accesoria, $1^{\text {a }}$ ed., Madrid (Edersa Instituto de Criminología), 1999, pp. 507 y ss. En la doctrina minoritaria que admite esta responsabilidad, entre otros: DOPICO GÓMEZ-ALLER, J., Omisión e injerencia en Derecho penal, cit., pp. 758-759; SÁNCHEZ-VERA GÓMEZ-TRELLES, J., «En los límites de la inducción», InDret, núm. 2, 2012, pp. 31 y ss.

29 Vid., entre otros, DOPICO GÓMEZ-ALLER, J., Omisión e injerencia en Derecho penal, cit., p. 121. Remarca la ausencia de la «cláusula de correspondencia»-como introducida en el ordenamiento alemán al § 13 I StGB -en el ordenamiento italiano: SGUBBI, F., Responsabilitá penale per omesso impedimento dell'evento, $1^{\text {a }}$ ed., Padova (Cedam), 1975, pp. 129-130.

30 Así como el significado de la «cláusula de correspondencia» según el § 13 I StGB queda «controvertido y poco esclarecido»: ROXIN, C., Derecho penal. Parte general. Tomo II. Especiales formas de aparición de delito, cit., p. 927. 
de parte especial ${ }^{31}$, para otros es también un problema de auténtica equiparación, en términos de disvalor, entre conductas omisivas y conductas activas ${ }^{32}-$, pero lo importante es que la jurisprudencia ha empezado a tomarlo cada vez más en serio ${ }^{33}$. Y, como es evidente, el alcance de cualquier norma penal incriminadora se ve recortado por cualquier elemento que se añade a ella, especificándola (en términos descriptivos/normativos).

En consecuencia, en lo que respecta a la comisión por omisión del delito doloso ajeno, hay un «cuadro impresionista».

Por un lado, hay supuestos de equivalencia (a la autoría), en los que el garante puede responder por dolo y, lo que interesa, por imprudencia, si el delito cometido por el autor es sancionado también a título de imprudencia: la diferencia entre los títulos de imputación subjetiva no conduce a la impunidad, pudiendo imputar el resultado (el delito doloso) al garante, como autor en comisión por omisión, a título de imprudencia ${ }^{34}$; no operando, en estos supuestos, la «prohibición de regreso» ${ }^{35}$. Por otro lado, hay supuestos de no equivalencia, en teoría no punible ex art. $11 \mathrm{CP}$. Y se considere que hay un sector de la doctrina según el cual nunca hay equivalencia entre la omisión del garante y la comisión del delito del tercero (autorresponsable) ${ }^{36}$, ya que el «omitente [...] se encuentra ante un curso causal lesivo dominado por un autor principal que comete una acción dolosa ${ }^{37}$, y hay otro sector que sostiene que no hay equivalencia cuando el garante es de control sobre una fuente de peligro $^{38}$.

31 Por todos, PEÑARANDA RAMOS, E., «La tipicidad en los delitos omisivos», en Memento práctico Francis Lefebvre. Penal 2019, cit., p. 180. Cfr. en la doctrina alemana, con respecto al § 13 I StGB: JESCHECK, H.; WEIGEND, T., Tratado de Derecho Penal. Parte general, cit., p. 678.

32 SILVA SÁNCHEZ, J. M., El nuevo Código penal: cinco cuestiones fundamentales, $1^{\text {a }}$ ed., Barcelona (José María Bosch Editor), 1997, pp. 52, 67.

33 TOMÁS-VALIENTE LANUZA, C., «Artículo 11», en GÓMEZ-TOMILLO, M., Comentarios prácticos al Código penal. Parte general, t. I, Cizur Menor (Thomson Reuters Aranzadi), 2015: «la tendencia [a, una vez apreciada la posición de garantía, afirmar la equivalencia sin mayores disquisiciones] parece, con todo, comenzar a corregirse en los últimos años». En la jurisprudencia más reciente, por ejemplo: STS 758/2018, de 9 de abril 2019; STS 464/2018, de 15 de octubre; STS 682/2017 de 18 de octubre; STS 482/2017 de 28 de junio.

${ }^{34}$ Al respecto, habla de «yuxtaposición de responsabilidades imprudentes [...] con otras dolosa» GIMBERNAT ORDEIG, E., Estudios sobre el delito de omisión, cit., p. 247.

35 Admiten esta excepción a la tipicidad de la cooperación imprudente en un delito doloso (o imprudente) ajeno: ROCA DE AGAPITO, L., Las acciones cotidianas como problema de la participación criminal, $1^{\mathrm{a}}$ ed., Valencia (Tirant lo Blanch), 2013, p. 79; MARAVER GÓMEZ, M., «Concepto restrictivo de autor y principio de autorresponsabilidad», en Homenaje al profesor Dr. Gonzalo Rodríguez Mourullo, 1ª ed., Cizur Menor (Civitas), 2005, pp. 643-644.

36 Así optando siempre por la «participación» del garante: vid. las referencias en SILVA SÁNCHEZ, J. M., «Aspectos de la comisión por omisión: fundamento y formas de intervención. El ejemplo del funcionario penitenciario», cit., p. 386, nota 90 .

37 RUEDA MARTÍN, M. A., ¿Participación por omisión? Un estudio sobre la cooperación por omisión en un delito de acción doloso cometido por un autor principal, cit., p. 90, desarrollando la tesis expuesta por GALLAS, W., «Strafbares Unterlassen im Fall einer Selbsttötung» JuristenZeitung, 1960, p. 687.

38 Por todos: PEÑARANDA RAMOS, E., «La tipicidad en los delitos omisivos», cit., pp. 190-191; SILVA SÁNCHEZ, J. M., El delito de omisión. Concepto y sistema, cit., pp. 224-225. Acerca de la «teoría del 
A este respecto, sin embargo, la doctrina y la jurisprudencia observan que existen las normas sobre la participación delictiva -mejor dicho, intervención delictiva ${ }^{39}$ - que «interfieren ${ }^{40} \gg$ con la comisión por omisión, aunque para un sector relevante de la doctrina es dogmáticamente incorrecto el recurso a la participación delictiva para estos supuestos ${ }^{41}$.

Ahora bien, aquí se comparte la tesis que exige para el castigo de la participación, tal y como la regula el Código Penal español, el elemento subjetivo del dolo ${ }^{42}$. De acuerdo con ello, es la ausencia de dolo la que se erige en verdadera barrera frente a la imputación del resultado-delito no impedido -si hay deber de garantía- o no dificultado -si no hay deber de garantía, sino cooperación-complicidad por infracción de «mandatos menores» ${ }^{43}-$. Si no se exigiera el dolo para castigar la participación, como sostiene parte de la doctrina ${ }^{44}, \mathrm{o}$ si se aceptase una concepción unitaria del autor en los delitos imprudentes, transformando cualquier aporte imprudente al resultado final en una autoría ${ }^{45}$-lo que ocurrió, además, en el «caso Vinader» ${ }^{46}$-, sería imprescindible encontrar otra barrera para no vulnerar el principio de autorresponsabilidad, probablemente en el marco de la imputación objetiva ${ }^{47}$ : pero esto escapa de esta reflexión.

contenido de deber», vid. también MAÑALICH RAFFO, J. P., «Omisión del garante e intervención delictiva. Una reconstrucción desde la teoría de las normas», cit., p. 264 y ss.

39 Más correctamente, distingue entre la fundamentación del carácter típico de la intervención delictiva y la decisión sobre la forma de su castigo a título de autoría o de participación, ROBLES PLANAS, R., Garantes y cómplices. La intervención por omisión y en los delitos especiales, cit., pp. 55 y ss.

40 En la doctrina italiana, RISICATO, L., Combinazione e interferenza di forme di manifestazione del reato, cit., pp. 152 y ss., distingue entre «combinación» e «interferencia» de normas de parte general. En la segunda hipótesis -lo que ocurre, por ejemplo, entre el art. 40.2 y el art. 110 Código penal italiano- hay un efecto de extensión de la originaria tipicidad penal especialmente importante.

${ }_{41}$ Véase, por todos, la crítica de KAUFMANN, A., Dogmática de los delitos de omisión, $1^{\text {a }}$ ed., Madrid (Marcial Pons), 2006, pp. 297 y ss.

42 Por todos, PÉREZ MANZANO, M., Autoría y participación imprudente en el Código penal del 1995, $1^{\text {a }}$ ed., Madrid (Civitas), 1999, pp. 81 y ss. Vid. también RUEDA MARTíN, M. A., ¿Participación por omisión? Un estudio sobre la cooperación por omisión en un delito de acción doloso cometido por un autor principal, cit., pp. 133 y ss.

${ }_{43}$ LASCURAÍN SÁNCHEZ, J. A., «La responsabilidad penal individual en los delitos de empresa», cit., pp. 101-102.

44 Vid. FEIJOO SÁNCHEZ, B., «La participación imprudente y la participación en el delito imprudente en el derecho penal», en El nuevo derecho penal español: estudios penales en memoria del profesor José Manuel Valle Muñiz, 1 ${ }^{\text {a }}$ ed., Alcanò (Aranzadi), 2001, pp. 229 y ss.; ROBLES PLANAS, R., «Participación en el delito de imprudencia», $R D P C$, núm. 6, 2000, pp. 234 y ss. En cambio, MIR PUIG, S., Derecho penal. Parte general, cit., pp. 387-389, admite la cooperación necesaria imprudente, pero no la complicidad.

45 Por todos, GIMBERNAT ORDEIG, E., Estudios sobre el delito de omisión, cit., pp. 247-250.

46 Vid., críticamente, SÁNCHEZ-VERA GÓMEZ-TRELLES, J., «Caso Vinader», en Casos que hicieron doctrina en derecho penal, $2^{\text {a }}$ ed., Madrid (La Ley), 2011, pp. 267 y ss. en relación a SAN de 17 de noviembre 1981, confirmada por STS 98/1983 de 29 de enero.

47 Así plantea la cuestión la doctrina alemana dominante; vid. las referencias en PEÑARANDA RAMOS, E., La participación en el delito y el principio de accesoriedad, $1^{\text {a }}$ ed., Madrid (Tecnos), 1990, pp. 272 y ss. 
Dicho esto, la omisión del garante no equivalente a la autoría activa en el delito doloso del tercero puede convertirse estructuralmente en una simple participación en el delito ${ }^{48}$, siendo equivalente a una participación activa: en estos casos las normas sobre la intervención delictiva pueden indiferentemente ser leídas como normas de criminalización de conductas atípicas, que no superan el juicio de equivalencia requerido ex art. $11 \mathrm{CP}^{49}$, o simplemente como normas con función definitoria en el marco de la comisión por omisión, distinguiendo entre equivalencia con la autoría y equivalencia con la participación ${ }^{50}$. Así ha razonado una línea jurisprudencial, esencialmente a partir de la STS 1538/2000 de 9 de octubre ${ }^{51}$, y así plantea la cuestión la doctrina mayoritaria, que niega una concepción unitaria del autor en la (comisión por) omisión ${ }^{52}$ : se trata de la llamada «prohibición de sobrevaloración del aporte ${ }^{53}$. Si es así, sin embargo, lo que queda fuera de la participación punible es el mundo de las omisiones imprudentes del garante consideradas como no equivalentes (a la autoría): estas son equiparada, desde el punto de vista legislativo, a la participación imprudente (impune-atípica) de un tercero no-garante ${ }^{54}$.

\section{El primer «residuo»: las omisiones imprudentes de garante no equivalentes}

Interesa, por lo tanto, analizar la colocación dogmática de este primer «residuo» de la interferencia entre las regulaciones de la comisión por omisión y de la intervención delicti-

48 Contra, con arreglo a la estructura de la omisión, BUSTOS RAMÍREZ, J.; HORMAZÁBAL MALARÉE, H., Lecciones de derecho penal. Parte general, $2^{\mathrm{a}}$ ed., Madrid (Editorial Trotta), 2006, pp. 415-416.

49 Vid. VIVES ANTÓN, T. S., «Artículo 11. Introducción», cit.

50 En este último sentido: LÓPEZ PEREGRÍN, M. C., La complicidad en el delito, cit., p. 345; SILVA SÁNCHEZ, J. M., «Aspectos de la comisión por omisión: fundamento y formas de intervención. El ejemplo del funcionario penitenciario», cit., p. 389.

51 Antes de la vigencia del Código penal de 1995, cfr. STS 507/1981 de 10 de abril. Más recientemente: STS 758/2018, de 9 de abril 2019; STS 482/2017 de 28 de junio.

52 Supra, notas 39 y 51 . Con respecto a las omisiones que, junto a la conducta del tercero autorresponsable, adquieren el sentido de formar parte de un delito, distingue entre casos (la mayoría) de «limitada capacidad de configurar el hecho» - participación-y casos (la minoría) de «relevante capacidad de configurar el hecho» -autoría-: ROBLES PLANAS, R., Garantes y cómplices. La intervención por omisión y en los delitos especiales, cit., pp. 72 y ss.

53 SÁNCHEZ-VERA GÓMEZ-TRELLES, J., «Intervención omisiva, posición de garante y prohibición de sobrevaloración del aporte», $A D P C P, 1995$, pp. 230 y ss. En cambio, defiende la tesis (minoritaria) por la que el omitente, en comisión por omisión, es siempre autor (teoría del delito de «infracción de deber»): ROXIN, C., Derecho penal. Parte general. Tomo II. Especiales formas de aparición de delito, cit., pp. 801 y ss.

54 Véase también HERNÁNDEZ BASUALTO, H., «Deberes de cuidado independientes del posible comportamiento posterior de otro y autoría imprudente (accesoria)», en Homenaje al profesor Dr. Gonzalo Rodríguez Mourullo, $1^{\text {a }}$ ed., Cizur Menor (Editorial Civitas), 2005, p. 608: «al margen de la bondad de las razones en favor de un concepto restrictivo de autor en materia de imprudencia y, sobre todo, de la justicia de prever penas diferenciadas para actores principales y accesorios, surge una legítima preocupación por ciertas posibles consecuencias indeseables de su afirmación a la luz de las dudas sobre la actual existencia de cobertura jurídico-penal para las formas de participación imprudente. La perspectiva de que toda forma de participación imprudente, con independencia de su importancia, sea sencillamente atípica no puede resultar satisfactoria». 
va: la omisión del garante que no es equivalente (a la autoría activa) y tampoco es dolosa. Por eso, en principio, serían posibles diferentes soluciones, más o menos «dogmáticamente correctas», como alternativas a la impunidad por atipicidad ${ }^{55}$ :

a) Subsunción en delitos de omisión pura. La dificultad de esta solución está en el hecho de que los delitos de omisión pura relacionados con deberes de impedir delitos -como los art. $176 \mathrm{CP}$ (permisión de la tortura), $407 \mathrm{CP}$ (abandono del destino para no impedir delitos), $450 \mathrm{CP}$ (omisión del deber de impedir delitos)no son expresamente castigados a título de imprudencia ${ }^{56}, \mathrm{o}$, mejor dicho, parecen requerir una representación del delito ajeno - quizás excepto para el art. $412.3 \mathrm{CP}$ (denegación de auxilio a un particular para evitar un delito)-. Además, subsumiendo la conducta omisiva en el art. $450 \mathrm{CP}$ se equipararía la omisión del garante, responsable por auto-organización o por deber institucional, a la omisión de un simple deber de solidaridad ${ }^{57}$; dicho en otra manera, se equipararía una omisión pura de garante a una omisión pura general ${ }^{58}$.

b) Subsunción en comisión por omisión de delitos de peligro. El inconveniente de esta solución podría ser que así se ignora el desvalor añadido por no haber impedido el resultado-delito del tercero. Véase, por ejemplo, el «caso de la colza» ${ }^{59}$ donde la condena se limitó a un delito de peligro para la salud pública (art. 346 antigua redacción $\mathrm{CP}$ ) en comisión por omisión ${ }^{60}$.

c) Absorción de la imprudencia en el dolo eventual. Por esa solución, cabe observar la jurisprudencia y imaginarse, por ejemplo, si el juez, en caso de pasividad entre cónyuges ante la comisión de un delito por parte de uno de ellos sobre el hijo menor $^{61}$, distinguiría del mismo modo entre equivalencia a la autoría - punibilidad-y no equivalencia (es decir, equivalencia a la participación) -impunidad-, optando

55 Así se admite que los bienes jurídicos (personales, porque solo por esta categoría el legislador en la parte especial generalmente establece el castigo a título de imprudencia) violados por el delito doloso del tercero no impedido por el garante imprudente y no equivalente merezcan una protección menos intensa comparada a la que reciben los mismos bienes cuando la omisión del garante es considerada equivalente a la autoría.

56 Característica de la mayoría de los delitos omisivos propios: LUZÓN PEÑA, D., Lecciones de derecho penal. Parte general, cit., p. 601; MUNOZ CONDE, F.; GARCÍA ARÁN, M., Derecho penal. Parte general, $9^{a}$ ed., Valencia (Tirant lo Blanch), 2015, p. 231.

57 JAKOBS, G., «La imputación penal de la acción y de la omisión», cit., pp. 850-851.

58 SILVA SÁNCHEZ, J. M., El delito de omisión. Concepto y sistema, cit., pp. 339 y ss.

59 STS 1996/1992, de 29 de abril.

60 Sobre este caso, PEÑARANDA RAMOS, E., «Sobre la responsabilidad en comisión por omisión respecto de hecho delictivos cometidos en la empresa (y en otras organizaciones)», en Derecho y justicia penal en el siglo XXI. Liber amicorum en homenaje al profesor Antonio González-Cuéllar García, $1^{\mathrm{a}}$ ed., Madrid (Editorial Colex), 2006, pp. 414 y ss.

${ }_{61}$ Infra, nota 83. De todas formas, se ha registrado una línea jurisprudencial que, en relación a este tipo de casos, afirma que la posición de garante genera responsabilidad a título de autoría: ROBLES PLANAS, R., Garantes y cómplices. La intervención por omisión y en los delitos especiales, cit., pp. 45-47, mencionando STS 481/1997 de 15 de abril. 
por la segunda calificación, si el dolo del garante «pasivo» no fuera comprobado, sino la mera imprudencia.

d) Admisión de la participación imprudente. Así planteando, cabe darse cuenta de que también los omitentes no-garantes serían punibles, a menos que se delimite la responsabilidad al nivel de la imputación objetiva ${ }^{62}$.

Hay que dar cuenta de que la solución más práctica seguida por la jurisprudencia y por parte de la doctrina es una interpretación reductiva del «juicio de equivalencia», en el sentido de entender la equivalencia como un problema de subsunción en los delitos de la parte especial y no como un problema de significado valorativo de la omisión: se admite, o sea, que hay siempre equivalencia por los delitos puros de resultado ${ }^{63}$, entre los que se encuentran los principales delitos castigados a título de imprudencia, de manera que se califican como autoría en comisión por omisión todas las omisiones imprudentes de los garantes $^{64}$; o, por lo menos, de los garantes de protección ${ }^{65}$.

\section{El segundo «residuo»: las omisiones imprudentes de garante no castigadas por la Ley, a título de imprudencia}

Además - pero esto es un aspecto transversal a los garantes equivalentes y no equivalentes- puede existir otro «residuo». Cuando se trata de responsabilidad omisiva por el hecho doloso del tercero, (aunque hay equivalencia) puede ocurrir que aquel delito no sea castigado a título de imprudencia; piénsese en los delitos contra la libertad, contra la libertad e indemnidad sexuales, contra el patrimonio y contra el orden socio-económico.

${ }^{62}$ FEIJOO SÁNCHEZ, B., «La participación imprudente y la participación en el delito imprudente en el derecho penal», cit., pp. 267-268.

${ }^{63}$ En doctrina, por ejemplo: LASCURAíN SÁNCHEZ, J. A., «Omisiones equivalentes», cit., p. 680. En jurisprudencia, STS 459/2018, de 10 de octubre.

${ }_{64}$ Evidencia esta tendencia en casos de responsabilidad del delegante por hechos del delegado.: LUZÓN PEÑA, D., Lecciones de derecho penal. Parte general, cit., p. 653. En doctrina, se califican algunos intervinientes imprudentes como autores (accesorios) cuando «no tiene sentido hablar [...] de una "contribución" o "aporte" al hecho de otro, porque [...] se está frente a la producción directa (no mediada por la actuación de otro) de una situación de peligro en sí intolerable para los bienes jurídicos en cuestión, lo que no se modifica porque en la actualización del riesgo en daño intervenga otro sujeto igualmente responsable»: HERNÁNDEZ BASUALTO, H., «Deberes de cuidado independientes del posible comportamiento posterior de otro y autoría imprudente (accesoria)», cit., p. 613. En sentido similar, ROBLES PLANAS, R., Garantes y cómplices. La intervención por omisión y en los delitos especiales, cit., pp. 72-74. Cfr. también GIMBERNAT ORDEIG, E., Estudios sobre el delito de omisión, cit., pp. 247-250.

Sobre la crítica a la «sobrevaloración del aporte», cfr.: SÁNCHEZ-VERA GÓMEZ-TRELLES, J., «Intervención omisiva, posición de garante y prohibición de sobrevaloración del aporte», cit., passim; GIMBERNAT ORDEIG, E., «Recensión a E. Bacigalupo, Delitos impropios de omisión», ADPCP, 1970, p. 725.

65 Vid. PEÑARANDA RAMOS, E., «La tipicidad en los delitos omisivos», cit., pp. 190-191, desarrollando las observaciones de SCHÜNEMANN, B., Fundamento y límites de los delitos de omisión impropia, $1^{\text {a }}$ ed., Madrid (Marcial Pons), 2009, pp. 371 y ss. 
En tal caso la imposibilidad de imputar al garante la no evitación (por imprudencia) de un delito - maltratos, robo con violencia, detención ilegal- puede parecer curiosa, comparada a la posibilidad de imputar la no evitación (por imprudencia) de un delito de igual o menor gravedad; piénsese en las lesiones. Cabe preguntarse si la elección del legislador, en el marco de la parte especial, sobre los títulos de imputación subjetiva, mantenga su coherencia, o dé lugar a consecuencias aleatorias, cuando se refleja sobre la responsabilidad imprudente de los garantes por no haber impedido el delito ajeno. La cuestión es: ¿la exclusión de la punibilidad, por ejemplo, de la realización por imprudencia de la mayoría de los delitos contra el patrimonio ${ }^{66}$, contra la libertad o contra la libertad e indemnidad sexuales abarca, desde una perspectiva de política criminal razonable, también las conductas de los actores «de segundo nivel», o sea de quien tiene el deber de impedir que otra persona, plenamente autorresponsable, cometa aquellos delitos? Por supuesto se podría incluso responder: sí, $a$ fortiori; pero queda una cuestión abierta.

Sin embargo, la generación de una responsabilidad plurisubjetiva a través la comisión por omisión y la intervención delictiva conduce a lo siguiente: no se imputa al garante imprudente el delito del tercero, si este delito no es castigado a título de imprudencia -maltratos; violación; detención ilegal; robo con violencia-; aun cuando fuera castigado por imprudencia -lesiones, homicidio, incendios- no se le imputa si la omisión no supera el juicio de equivalencia (con la autoría), porque la participación (omisiva) del garante es tan atípica como la participación (omisiva) del no-garante. Las dos cuestiones a menudo se sobreponen, porque, como se sabe, lo que no es considerado equivalente en forma omisiva por la formulación literal -delitos con modalidades específicas de comisión, como la violación, el robo con violencia o la estafa- tendencialmente no es castigado a título de imprudencia, destinada a delitos puramente resultativos como el homicidio o las lesiones. Pero hay casos más dudosos, como el delito de incendio ${ }^{67}$.

De todas formas, no se quiere sostener que en general la imputación al garante del delito no impedido por imprudencia sea la solución justa o satisfactoria, desde un punto de vista de política criminal. Se quiere simplemente describir lo que ocurre cuando se imputan al garante imprudente los delitos ajenos de vez en cuando: en otras palabras, las consecuencias de la «imprudencia en función de resultado» y de la llamada «lotería penal» ${ }^{68}$. Cabe

${ }^{66}$ Se recuerda que, excepcionalmente, el art. $267 \mathrm{CP}$ castiga el daño causado por «imprudencia grave en cuantía superior a 80000 euros».

${ }_{67}$ Vid. RODRÍGUEZ MOURULLO, G., Derecho penal: parte general, $1^{\text {a }}$ ed., Madrid (Civitas), 1978, pp. 315-316.

68 «A parità di violazione di regole cautelari (di disvalore della condotta) la risposta dell'ordinamento può essere incanalata da fattori casuali su binari profondamente diversi: affermazione di responsabilità penali anche molto gravi, se l'evento si è sfortunatamente verificato, e impunità se per fortuna l'evento non si è verificato, pur in presenza di inosservanze molto gravi. La responsabilità per colpa appare come una sorta di lotteria penale, moralmente discutibile»: PULITANÒ, D., Diritto penale, $8^{\mathrm{a}}$ ed., Torino (Giappichelli), 2019, p. 290. 
plantearse, entonces, por qué el garante, en el marco del mismo deber de garantía, debería prevenir $^{69}$ ciertos resultados-delitos y no otros.

La vía para salir del impasse podría consistir en considerar que el deber de garantía, en sentido ascendente, se construyera con miras a la protección de ciertos bienes jurídicos y no de otros ${ }^{70}$, por mucho que esto produjera restricciones también en relación con las omisiones dolosas del garante. Dicho planteamiento podría tener sentido en relación con los muchos «deberes de protección»: la madre que tiene que preservar la integridad física/ mental de su hijo, y no su integridad patrimonial ${ }^{71}$ o su libertad, no tendría el deber (de cuidado) de evitar hurtos o detenciones ilegales hacia su hijo. En cambio, se vuelve más discutible en relación con los «deberes de control»-el arma imprudentemente desatendida puede servir para hurtar con violencia, para detener ilegalmente y no solo para lesionar o matar-y todavía más discutible en cuanto a los «deberes institucionales» par excellence: sería paradójico afirmar que el funcionario policial -si lo consideramos garante ${ }^{72}$ - tiene el deber (de cuidado) de impedir lesiones y homicidios, es decir infracciones a la integridad física de los ciudadanos, y no la mayoría de los delitos contra el patrimonio o contra la libertad e indemnidad sexuales. En este sentido, resulta comprensible la opción del legislador por tipificar, en los casos de funcionarios o autoridades públicas, específicos delitos de omisión pura frente a la comisión de cualquier delito ajeno (omisión de impedir delitos ex art. $408 \mathrm{CP}$; denegación de auxilio ex art. 412 , n. 3 co. 1, co. 2, co. $3 \mathrm{CP}^{73}$ ).

En otro sentido, cabe imaginar que la reflexión de Silva Sánchez sobre la oportunidad de iure condendo de codificar (¿más? ${ }^{74}$ ) omisiones puras de garante ${ }^{75}$ venga a colación

69 Por un enfoque sobre las omisiones como no-prevenciones de eventos, en contra a una lectura causal de las omisiones, vid. MOORE, M., Causation and Responsibility. An essay in Law, Morals, and Metaphysics, cit., pp. 52 y ss.

${ }^{70}$ Así recordando que, por el garante, el deber de impedir ciertos delitos es simplemente un aspecto del (más general) deber de garantía: PULITANÒ, D., Diritto penale, cit., p. 214.

71 Vid. PELISSERO M., «Reati omissivi», en GROSSO, C. F.; PELISSERO, M.; PETRINI, D.; PISA, P., Manuale di diritto penale. Parte generale, 2a ed., Milano (Giuffrè), 2017, p. 217.

72 Resume las diferentes posturas sobre la cuestión, en la doctrina española: PEÑARANDA RAMOS, E., «Homicidio», en BAJO FERNÁNDEZ, M., Compendio de derecho penal. Parte especial, vol. I, 1ª ed, Madrid (Centro de Estudios Ramón Areces), 2003, pp. 109, 116 s.; en la doctrina italiana: LEONCINI I., Obbligo di attivarsi, obbligo di garanzia e obbligo di sorveglianza, $1^{\text {a }}$ ed., Torino (Giappichelli), 1999, pp. 134-150.

73 Sin embargo, hay que dar cuenta que el articulo diferencia las penas en relación con el tipo de delito no evitado -más grave en caso de delito contra la vida (art. 412, n. 3 co. $1 \mathrm{CP}$ ), menos grave en caso de delito contra la integridad, libertad sexual, salud o libertad de las personas (art. 412, n. 3 co. 2 CP), y aún menos grave en caso de cualquier otro delito (art. 412 , n. 3 co. $3 \mathrm{CP}$ ).

74 Los artículos 195.3 y 196 CP ya pueden representar ejemplos de «omisiones puras de garante»: SILVA SÁNCHEZ, J. M., «Entre la omisión de socorro y la comisión por omisión. Las estructuras de los arts. 195.3 y 196 del Código penal», en Problemas específicos de la aplicación del Código Penal, Madrid (Consejo General del Poder Judicial), 1999, pp. 154 y ss. Vid., en términos parcialmente diferentes, HUERTA TOCILDO, S., Principales novedades de los delitos de omisión en el código penal de 1995, $1^{\mathrm{a}}$ ed., Valencia (Tirant lo Blanch), 1997, pp. 40 y ss., 65 y ss.

75 SILVA SÁNCHEZ, J. M., El delito de omisión. Concepto y sistema, cit., pp. 339 y ss. De acuerdo con la oportunidad de codificar las «omisiones puras de garante», vid. también: DOPICO GÓMEZ-ALLER, J., 
precisamente por estos casos: cuando no se imputa al garante imprudente el delito del tercero, si no es castigado a título de imprudencia -maltratos; violación; detención ilegal; robo con violencia-; o cuando, aunque el delito sea castigado por imprudencia-lesiones, homicidio, incendios- no se le imputa si la omisión no supera el juicio de equivalencia, siendo equiparada, en cuanto a la atipicidad, a la participación imprudente de un tercero no-garante ${ }^{76}$. De este modo, la clase de obligaciones de «competencia preferente»-entre las de «competencia plena» y de «competencia mínima»- sería construida no a partir de una evaluación abstracta de la intensidad y gradualidad de los deberes ${ }^{77}$, que queda opinable, sino a partir de casos de lagunas axiológicas, es decir de lo que el legislador ha excluido del alcance de la comisión por omisión y de la participación punible. La cuestión podría asumir mayor relevancia práctica después un estudio sobre la existencia de un posible recurso indebido a la forma dolosa (eventual) por parte de la jurisprudencia: si, y con qué frecuencia, «ante la alternativa de dejar sin castigo conductas injustas y reprochables, aunque no dolosas, o de castigarlas a título de un dolo inexistente [...] los Tribunales elijan este segundo camino» ${ }^{78}$.

Dando unos ejemplos de los mencionados «residuos», se intentará explicar su tratamiento jurídico.

Caso 1 - El encargado de la seguridad. Un encargado de la seguridad en la entrada de un tribunal omite imprudentemente detener a un sujeto que lleva un arma en su maleta. Esta persona, luego de entrar, lesiona a algunas personas y mata a otras ${ }^{79}$. Imagínese ahora, en cambio, que esta persona, en lugar provocar la muerte de otra persona, comete un robo con violencia y una detención ilegal.

«Criminal omissions: a european perspective», New Criminal Law Review, vol. 11, núm. 3, 2008, pp. 446 y ss.; ROBLES PLANAS, R., Garantes y cómplices. La intervención por omisión y en los delitos especiales, cit., pp. 99-103. Cfr. también COCA VILA, I., La colisión de deberes en derecho penal. Concepto y fundamentos de solución, $1^{\mathrm{a}}$ ed., Barcelona (Atelier), 2016, pp. 296-304.

76 Vid. SILVA SÁNCHEZ, J. M., «Aspectos de la comisión por omisión: fundamento y formas de intervención. El ejemplo del funcionario penitenciario», cit., p. 393: «La excepción la plantean los tipos que no son comisibles por imprudencia (ni por omisión), a propósito de los cuales habría que plantear el tema de la punibilidad de la intervención imprudente en delitos dolosos (y, aquí, además, imprudencia omisiva)» y específicamente nota 122 «En nuestro caso, si se llegara a la conclusión de que no cabe la intervención omisiva imprudente, habría que acudir a las omisiones puras agravadas (por imprudencia)».

77 Como, recientemente, en COCA VILA, I., La colisión de deberes en derecho penal. Concepto y fundamentos de solución, cit., pp. 276 y ss.

78 SILVA SÁNCHEZ, J. M., El nuevo Código penal: cinco cuestiones fundamentales, cit., p. 90. Cfr. también SCHÜNEMANN, B., Fundamento y límites de los delitos de omisión impropia, cit., p. 238, donde se remarca una conexión en el siguiente sentido: «el legislador de los últimos cien años habría creado muchos más tipos de omisión propia, limitando así e contrario el delito de omisión impropia, si la jurisprudencia no hubiera accedido en seguida a toda necesidad de punición real o supuesta extendiendo el delito de omisión impropia».

79 El caso descrito coincide con lo de la sentencia Corte di appello di Brescia, 2900/2018, de 29 de octubre. 
El tratamiento jurídico de las dos idénticas omisiones imprudentes del encargado de la seguridad (garante) es diferente, por el hecho casual de que el autor doloso cometa un delito (castigado a título de imprudencia, como las lesiones) y no otro (no castigado a título de imprudencia, como un robo con violencia o una detención ilegal). En el segundo caso, además, tampoco sería aplicable un delito de omisión propia, por falta de dolo. Y, de todas formas, si las omisiones en ambos casos fueran consideradas equivalentes a conductas de mera participación, no podría castigarse a ninguna de ellas, aunque el encargado es garante.

Caso 2 - El empresario de fuegos artificiales. Un empresario de fuegos artificiales imprudentemente deja sin vigilancia sus productos pirotécnicos en un cobertizo abierto y accesible a terceros. Producto de ello, dos sujetos roban los artículos desatendidos e incendian el negocio de un hombre ${ }^{80}$.

El tratamiento jurídico del empresario (garante) depende del juicio de equivalencia de su omisión con la conducta de los terceros: en caso negativo -cómo podría sostener, por ejemplo, Mourullo ${ }^{81}$ - su no evitación imprudente del delito de incendio sería impune y equiparada, en cuanto a la atipicidad, a la participación imprudente del tercero no-garante.

Caso 3 - La policía que se demora. Un funcionario policial encargado de las llamadas de emergencia recibe una solicitud de auxilio de una mujer que está siendo amenazada por su pareja. En la primera hipótesis, el funcionario, por imprudencia, olvida transferir la solicitud de auxilio a una patrulla policial. En la segunda hipótesis, el funcionario transfiere la solicitud a la patrulla, cuyos funcionarios, por imprudencia, no se dirigen al lugar de los hechos. En ambos casos, la pareja de la mujer tiene tiempo suficiente para matar a la víctima $\mathrm{o}$, alternativamente, para detenerla ilegalmente.

El tratamiento jurídico de los funcionarios policiales imprudentes depende de que se les considere o no garantes. En caso afirmativo, a los funcionarios se les puede imputar-si se los considera autores; de lo contrario serían partícipes impunes equiparados a terceros no-garantes- solo la no evitación de los delitos castigados a título de imprudencia; por los otros delitos, pueden responder por el delito de omisión pura ex art. $412.3 \mathrm{CP}$. En caso negativo, los funcionarios reciben un tratamiento jurídico más uniforme: cometen un delito de omisión pura ex art. 412.3 CP.

Caso 4 - «Caso Alba». Un hombre comete un delito de lesiones y otro de tratos degradantes en contra del hijo de su pareja, quien conoce los hechos y no hace nada para impedirlos ${ }^{82}$. Imagínese ahora que la mujer no conocía los hechos pero habría podido fácilmente conocerlos.

80 Por unos casos similares en la jurisprudencia alemana, vid.: HERNÁNDEZ BASUALTO, H., «Deberes de cuidado independientes del posible comportamiento posterior de otro y autoría imprudente (accesoria)», cit., pp. 611-613.

81 Vid. RODRÍGUEZ MOURULLO, G., Derecho penal: parte general, cit., pp. 315-316.

82 STS 1061/2009, de 26 de octubre. 
El tratamiento jurídico de la mujer (garante) que imprudentemente no impide los delitos de la pareja sobre su hija depende del tipo de delito: por las lesiones puede responder -siempre que se la considere autora, de lo contrario sería partícipe impune como un tercero no-garante-; no por los tratos degradantes o cualquier delito no castigado a título de imprudencia (violación, detención ilegal). En el segundo caso, además, tampoco sería aplicable un delito de omisión pura, por falta de dolo.

\section{CONSECUENCIAS RELACIONADAS CON LA POLÍTICA CRIMINAL: LA PÉRDIDA DEL TESTIMONIO Y LA REDUCCIÓN DEL PRINCIPIO DE LA AUTORRESPONSABILIDAD}

Quedan estas dudas: si es verdad que en el proceso penal «la caza cuenta más que la presa, o sea la forma en la que se actúa cuenta más que el resultado» ${ }^{83}$, hay que reflexionar sobre si y cuánto es oportuno criminalizar -si solo por dolo o también por imprudencia, en los supuestos considerados- al omitente, porque a veces puede ocurrir que el suyo sea un testimonio útil para reconstruir los hechos; testimonio que (en teoría, o sea fuera de mecanismos de «justicia negociada») se podría perder si se le convierte en (co)acusado, con pleno derecho a guardar silencio y a no prestar declaración ${ }^{84}$. Huelga decir que la referencia es a la omisión -pura o impropia, a estos efectos no hay diferencia-temporalmente más próxima al hecho doloso, porque por omisiones considerablemente antecedentes (piénsese en el garante que deja sin supervisión el arma) es más improbable que el testimonio del omitente sea esencial. Un inconveniente de la política de penalización extensiva se ha visto, por ejemplo, cuando el legislador italiano optó por incriminar la conducta del inmigrante irregular, perdiendo así el testimonio (esencial) frente a los delitos de favorecimiento de la inmigración ilegal ${ }^{85}$. Criminalizar los dos «residuos» analizados, para obviar a las lagunas

83 Traducción libera de «la caccia vale più della preda e cioè il modo in cui si agisce conta più del risultato»: CORDERO, F., «Diatribe sul processo penale», en Ideologie del processo penale, $1^{\text {a }}$ ed., Milano (Giuffrè), 1966, p. 220.

${ }^{84}$ Sobre la ambigüedad del régimen jurídico de las declaraciones de los coacusados, que no coincide con el régimen de la prueba testifical, por todos: MORENO CATENA, V.; CORTÉS DOMÍNGUEZ, V., Derecho procesal penal, $8^{\text {a }}$ ed., Valencia (Tirant lo Blanch), 2017, pp. 439-440; GIMENO SENDRA, V.; DÍAZ MARTÍNEZ, M., Manual de derecho procesal penal, 2a ed., Madrid (Ediciones Jurídicas Castillo de Luna), 2018, pp. 605-606; ASENCIO MELLADO, J., Derecho procesal penal, 7ª ed., Valencia (Tirant lo Blanch), 2015, pp. 300-301.

${ }_{85}$ Vid. PARLATO, L., «Concussione/induzione: i punti deboli dell'accertamento processuale», en Riformulazione-frattura del delitto di concussione ex art. 317 c.p., ponencia pronunciada en el marco del workshop en la Università degli Studi di Milano-Bicocca. Disponible en $<$ https://www.penalecontemporaneo. it/d/3134-riformulazione-frattura-del-delitto-di-concussione-ex-art-317-cp > [Consultado el 16/09/2019]: «Gli effetti collaterali di siffatte manovre normative interessano soprattutto la testimonianza. Tramutando la vittima in correo, infatti, si provoca la perdita di un importante testimone, perché le dichiarazioni del loquens vanno a soggiacere al regime dell'esame delle parti, libero da obblighi (di rispondere e di dire la verità) e quindi circondato da maggiori sospetti, nonché attratto dallo statuto di cui agli artt. 210 e 192 co. 3 c.p.p. Di converso, l'esame testimoniale è interdetto, oppure ridotto nell'incerto alveo delle dichiarazioni contra alios e, perciò, 
axiológicas, entonces podría ser no especialmente oportuno: el garante que no es sancionado por la atipicidad de la participación imprudente o por el sistema numerus clausus de la imprudencia puede convertirse en fuente de prueba (si bien probablemente no directamente en relación al hecho principal, el delito doloso ajeno, como no hay una representación de eso en supuestos de no evitación imprudente; pero tal vez en relación a indicios de eso).

Por otro lado, aunque la «prohibición de regreso» pacíficamente no opera en supuestos de deber de garantía ${ }^{86}$, es clara la compresión del principio de autorresponsabilidad penal - con arreglo al cual «a la hora de configurar la propia conducta nadie debe tener en cuenta el hecho de que un tercero esté decidido a cometer un delito» ${ }^{87}$ - en sancionar la no evitación imprudente del delito doloso ajeno, aún más, de lege ferenda, en los dos «residuos» descritos. La perspectiva se agravaría ulteriormente en los «failure to protect» casos, como el «caso Alba», donde el garante que no impide el delito frecuentemente es también víctima del mismo o otros delitos por parte del autor material ${ }^{88}$. Aquí la extensión de la responsabilidad penal puede generar éxitos iniquos, como los producidos por la aplicación de la Section 5 de la Domestic Violence, Crime and Victims Act $2004^{89}$ en supuestos de no

entro i confini della c.d. testimonianza assistita. Tali confini, di per sé problematici per la difficoltà di discernere i contenuti accusatori della deposizione, possono qui risultare particolarmente angusti in ragione di plausibili strategie difensive, propense al silenzio o alla negazione tout court dei fatti, dettate da una comprensibile cautela contro gli accentuati rischi di autoincriminazione».

86 Supra, nota 36.

87 ROBLES PLANAS, R., Garantes y cómplices. La intervención por omisión y en los delitos especiales, cit., p. 62, en relación a los supuestos problemáticos de omisión conjunta a la conducta delictiva del tercero autorresponsable. En suma, la preocupación es evitar «transferencias de responsabilidad y transferencias de penas [...] a personas que carecen de responsabilidad alguna por el delito cometido»: PÉREZ MANZANO, M.; CANCIO MELIÁ, M., «Principios del derecho penal (III)», en LASCURAÍN SÁNCHEZ, J. A., Manual de Introducción al Derecho Penal, $1^{\text {a }}$ ed., Madrid (Agencia Estatal Boletín oficial del Estado), 2019, p. 94.

88 HERRING J., «Familial Homicide, Failure to Protect and Domestic Violence: Who's the Victim?», The Criminal Law Review, 2007, pp. 923 y ss. Cfr. también ASHWORTH, A., «Positive duties, Regulation and the Criminal Sanction», Law Quarterly Review, 2017. Disponible en <https://uk.westlaw.com/ Document/I5518B5C0985E11E7BEB8FD7157D7F73E/View/FullText.html?navigationPath=Search\%2F v1\%2Fresults\%2Fnavigation\%2Fi0ad6ad3c0000016eac940822cfbc053d\%3FNav\%3DUK-JOURNALSPUBLICATION\%26fragmentIdentifier\%3DI5518B5C0985E11E7BEB8FD7157D7F73E\%26parentRan k\%3D0\%26startIndex\%3D1\%26contextData\%3D\%2528sc.Default\%2529\%26transitionType\%3DSearc hItem\&listSource $=$ Search\&listPageSource $=722 \mathrm{ad} 9 \mathrm{ffe} 45 \mathrm{af} 1119 \mathrm{fbc} 62 \mathrm{ffa} 48 \mathrm{ae} 7 \mathrm{~d} \&$ list=UK-JOURNALSPUBLICATION\&rank=12\&sessionScopeId $=9 \mathrm{e} 41 \mathrm{a} 23 \mathrm{ee} 01 \mathrm{fd} 8323 \mathrm{f0cf} 9904129 \mathrm{e} 4 \mathrm{a} 57049 \mathrm{e} 2 \mathrm{~d} 548283 \mathrm{~b} 1 \mathrm{bb} 2$ $8 \mathrm{e} 06601 \mathrm{e} 42075 \mathrm{~d} \&$ originationContext $=$ Search + Result\&transitionType=SearchItem \&contextData $=\% 28 \mathrm{sc}$. Default $\% 29 \&$ comp $=$ wluk $>$.

89 Se reporta la Section 5 de la Domestic Violence, Crime and Victims Act 2004:

«The offence

(1)A person ("D") is guilty of an offence if-

(a)a child or vulnerable adult ("V") dies [F1or suffers serious physical harm] as a result of the unlawful act of a person who-

(i)was a member of the same household as V, and

(ii)had frequent contact with him,

(b)D was such a person at the time of that act, 
evitación imprudente ${ }^{90}$. De acuerdo con eso, es suficiente que el sujeto -en la práctica, la madre- «ought to have been aware of the risk» (d, i) de la comisión del delito y «ought to have foreseen» (d, iii) las circunstancias: desde el literal se puede entender, entonces, porque la doctrina se ha planteado hasta qué punto un tal deber de cuidado sea exigible ${ }^{91}$. En fin, no parece una tarea fácil, para el legislador, elegir entre una extensión de la prevención penal, no solo hacia el autor doloso autorresponsable, sino también hacia el omitente (imprudente)

(c)at that time there was a significant risk of serious physical harm being caused to $\mathrm{V}$ by the unlawful act of such a person, and

(d)either D was the person whose act caused [F2the death or serious physical harm] or-

(i)D was, or ought to have been, aware of the risk mentioned in paragraph (c),

(ii)D failed to take such steps as he could reasonably have been expected to take to protect $\mathrm{V}$ from the risk, an

(iii)the act occurred in circumstances of the kind that $\mathrm{D}$ foresaw or ought to have foreseen.

(2)The prosecution does not have to prove whether it is the first alternative in subsection (1)(d) or the second (sub-paragraphs (i) to (iii)) that applies.

(3)If $\mathrm{D}$ was not the mother or father of $\mathrm{V}-$

(a)D may not be charged with an offence under this section if he was under the age of 16 at the time of the act that caused [F3the death or serious physical harm];

(b)for the purposes of subsection (1)(d)(ii) D could not have been expected to take any such step as is referred to there before attaining that age.

(4)For the purposes of this section-

(a)a person is to be regarded as a "member" of a particular household, even if he does not live in that household, if he visits it so often and for such periods of time that it is reasonable to regard him as a member of it;

(b)where V lived in different households at different times, "the same household as V" refers to the household in which $\mathrm{V}$ was living at the time of the act that caused [F4the death or serious physical harm].

(5)For the purposes of this section an "unlawful" act is one that-

(a)constitutes an offence, or

(b)would constitute an offence but for being the act of-

(i)a person under the age of ten, or

(ii)a person entitled to rely on a defence of insanity.

Paragraph (b) does not apply to an act of D.

(6)In this section-

"act" includes a course of conduct and also includes omission;

"child" means a person under the age of 16 ;

"serious" harm means harm that amounts to grievous bodily harm for the purposes of the Offences against the Person Act 1861 (c. 100);

"vulnerable adult" means a person aged 16 or over whose ability to protect himself from violence, abuse or neglect is significantly impaired through physical or mental disability or illness, through old age or otherwise.

(7)A person guilty of an offence under this section [F5 of causing or allowing a person's death] is liable on conviction on indictment to imprisonment for a term not exceeding 14 years or to a fine, or to both.

(8)A person guilty of an offence under this section of causing or allowing a person to suffer serious physical harm is liable on conviction on indictment to imprisonment for a term not exceeding 10 years or to a fine, or to both.»

90 En HERRING J., «Familial Homicide, Failure to Protect and Domestic Violence: Who's the Victim?», cit., pp. 926-926, se exponen casos de condenas a madres en relación a hechos cometidos en sus ausencia.

${ }_{91}$ HERRING J., «Familial Homicide, Failure to Protect and Domestic Violence: Who's the Victim?», cit., pp. 927 y ss. Más en general, ASHWORTH, A., «A New Generation of Omissions Offences?», cit., p. 364, afirma que la responsabilidad por omisión «should only be imposed on individuals if they are present or proximate, and have the ability to carry out that duty easily and without personal danger».

RJUAM, n. ${ }^{\circ}$ 40, 2019-II, pp. 77-100

ISSN: $1575-720-\mathrm{X}$ 
que no impide su delito, o una exigencia cognitiva, de mejor comprobación de los hechos y que ponga en valor el principio de autorresponsabilidad.

\section{BIBLIOGRAFÍA}

ASENCIO MELLADO, J., Derecho procesal penal, $7^{\mathrm{a}}$ ed., Valencia (Tirant lo Blanch), 2015.

ASHWORTH, A., «Positive duties, Regulation and the Criminal Sanction», Law Quarterly Review, 2017. Disponible en <https://uk.westlaw.com/Document/ I5518B5C0985E11E7BEB8FD7157D7F73E/View/FullText.html?navigationPa th $=$ Search\%2Fv1\%2Fresults\%2Fnavigation\%2Fi0ad6ad3c0000016eac940822 cfbc053d\%3FNav\%3DUK-JOURNALS-PUBLICATION\%26fragmentIdentifi er\%3DI5518B5C0985E11E7BEB8FD7157D7F73E\%26parentRank\%3D0\%26 startIndex\%3D1\%26contextData\%3D\%2528sc.Default\%2529\%26transitionTy pe\%3DSearchItem\&listSource $=$ Search\&listPageSource $=722 \mathrm{ad} 9 \mathrm{ffe} 45 \mathrm{af1} 119 \mathrm{fb}$ c62ffa48ae7d\&list=UK-JOURNALS-PUBLICATION\&rank=12\&sessionScop eId=9e41a23ee01 fd8323f0cf9904129e4a57049e2d548283b1bb28e06601e4207 $5 \mathrm{~d} \&$ originationContext $=$ Search + Result\&transitionType $=$ SearchItem\&contextD ata $=\% 28$ sc.Default $\% 29 \&$ comp $=$ wluk $>$ [Consultado el 28/11/2019].

ASHWORTH, A., «A New Generation of Omissions Offences?», The Criminal Law Review, 2018, pp. 354-364.

BACIGAlUPO ZAPATER, E., Derecho penal. Parte general, 2 ${ }^{\mathrm{a}}$ ed., Buenos Aires (Hammurabi), 1999.

BACIGALUPO ZAPATER, E., Delitos impropios de omisión, 2a ed., Madrid (Dykinson), 2006.

BISORI, L., «L'omesso impedimento di reato altrui nella dottrina e giurisprudenza italiane», en Rivista Italiana di Diritto e Procedura Penale, 1997, pp. 1339-1394.

BOBBIO, N., El problema del positivismo jurídico, $2^{\mathrm{a}}$ ed., México (D.F. Fontamara), 1992.

BUSTOS RAMÍREZ, J.; HORMAZÁBAL MALARÉE, H., Lecciones de derecho penal. Parte general, 2a ed., Madrid (Editorial Trotta), 2006.

CANCIO MELÍA, M., «Prevaricación judicial», en Memento práctico Francis Lefebvre. Penal 2019, $1^{\text {a }}$ ed., Madrid (Francis Lefebvre), pp. 1807-1813.

COCA VILA, I., La colisión de deberes en derecho penal. Concepto y fundamentos de solución, $1^{\text {a }}$ ed., Barcelona (Atelier), 2016. 
CORDERO, F., «Diatribe sul processo penale», en Ideologie del processo penale, $1^{\text {a }}$ ed., Milano (Giuffrè), 1966.

COUSO, J.; WERLE, G., Intervención delictiva en contextos organizados, $1^{\text {a }}$ ed., Valencia (Tirant lo Blanch), 2017.

DOPICO GÓMEZ-ALLER, J., Omisión e injerencia en Derecho penal, $2^{\mathrm{a}}$ ed., Valencia (Tirant lo Blanch), 2006.

DOPICO GÓMEZ-ALLER, J., «Criminal omissions: a european perspective», New Criminal Law Review, vol. 11, núm. 3, 2008, pp. 419-451.

FEIJOO SÁNCHEZ, B., «La participación imprudente y la participación en el delito imprudente en el derecho penal», en El nuevo derecho penal español: estudios penales en memoria del profesor José Manuel Valle Muñiz, $1^{\mathrm{a}}$ ed., Alcanò (Aranzadi), 2001, 229-272.

FLETCHER, G., Grammatica del diritto penale, 1ª ed., Bologna (Il Mulino), 2004.

GALLAS, W., «Strafbares Unterlassen im Fall einer Selbsttötung» JuristenZeitung, 1960, pp. 686-692.

GIMBERNAT ORDEIG, E., «Recensión a E. Bacigalupo, Delitos impropios de omisión», $A D P C P, 1970$, pp. 724-726.

GIMBERNAT ORDEIG, E., Estudios sobre el delito de omisión, $2^{\mathrm{a}}$ ed., Montevideo (Editorial B de F), 2013.

GIMENO SENDRA, V.; DÍAZ MARTÍNEZ, M., Manual de derecho procesal penal, $2^{\text {a }}$ ed., Madrid (Ediciones Jurídicas Castillo de Luna), 2018.

GIUNTA, F., Illiceità e colpevolezza nella responsabilità colposa, $1^{\text {a }}$ ed., Padova (Cedam), 1993.

GÓMEZ RIVERO, M., La inducción a cometer el delito, $1^{\mathrm{a}}$ ed., Valencia (Tirant lo Blanch), 1995.

GUNTHER, K., «De la vulneración de un derecho a la infracción de deber: ¿un "cambio de paradigma" en el derecho penal?», en La insostenible situación del derecho penal, 1ª ed., Granada (Editorial Comares), 2000, pp. 489-505.

HERNÁNDEZ BASUALTO, H., «Deberes de cuidado independientes del posible comportamiento posterior de otro y autoría imprudente (accesoria)», en Homenaje al profesor Dr. Gonzalo Rodríguez Mourullo, $1^{\text {a }}$ ed., Cizur Menor (Editorial Civitas), 2005, pp. 607-616.

HERRING J., «Familial Homicide, Failure to Protect and Domestic Violence: Who's the Victim?», The Criminal Law Review, 2007, pp. 923-933. 
HUERTA TOCILDO, S., Problemas fundamentales de los delitos de omisión, $1^{\text {a }}$ ed., Madrid (Ministerio de Justicia - Centro de Publicaciones), 1987.

HUERTA TOCILDO, S., Principales novedades de los delitos de omisión en el código penal de 1995, $1^{\text {a }}$ ed., Valencia (Tirant lo Blanch), 1997.

IACOVIELLO, F. M., «Processo di parti e prova del dolo», en Criminalia, 2010, pp. 463-509.

JAKOBS, G., «La imputación penal de la acción y de la omisión», $A D P C P$, vol. III, 1996, pp. 835-874.

JESCHECK, H.; WEIGEND, T., Tratado de Derecho Penal. Parte general, $5^{\text {a }}$ ed., Granada, (Editorial Comares), 2002.

JORGE BARREIRO, A., «Omisión e imprudencia. Comisión por omisión en la imprudencia: en la construcción y en la medicina en equipo», Cuadernos de derecho judicial. La comisión por omisión - separata, 1994.

KAUFMANN, A., Dogmática de los delitos de omisión, 1ª ed., Madrid (Marcial Pons), 2006.

LASCURAÍN SÁNCHEZ, J. A., Los delitos de omisión: fundamento de los deberes de garantía, $1^{a}$ ed., Madrid (Civitas), 2002.

LASCURAíN SÁNCHEZ, J. A., «Omisiones equivalentes», en Estudios de derecho penal. Homenaje al profesor Santiago Mir Puig, $1^{\text {a }}$ ed., Buenos Aires (Bdef), 2017, pp. 673-683.

LASCURAíN SÁNCHEZ, J. A., «La responsabilidad penal individual en los delitos de empresa», en Derecho penal económico y de la empresa, $1^{a}$ ed., Madrid (Dykinson), 2018, pp. 87-128.

LEONCINI I., Obbligo di attivarsi, obbligo di garanzia e obbligo di sorveglianza, $1^{\text {a }}$ ed., Torino (Giappichelli), 1999.

LÓPEZ PEREGRÍN, M. C., La complicidad en el delito, $1^{\text {a }}$ ed., Valencia (Tirant lo Blanch), 1997.

LUZÓN PEÑA, D., «La participación por omisión en la jurisprudencia reciente del TS», en Estudios penales, 1ª ed., Barcelona (PPU), 1991, pp. 225-250.

LUZÓN PEÑA, D., Lecciones de derecho penal. Parte general, $3^{\text {a }}$ ed., Valencia (Tirant lo Blanch), 2016.

MAÑALICH RAFFO, J. P., «Omisión del garante e intervención delictiva. Una reconstrucción desde la teoría de las normas», Revista de Derecho Universidad Católica del Norte, núm. 2, 2014, pp. 225-276. 
MARAVER GÓMEZ, M., «Concepto restrictivo de autor y principio de autorresponsabilidad», en Homenaje al profesor Dr. Gonzalo Rodríguez Mourullo, $1^{\mathrm{a}} \mathrm{ed}$., Cizur Menor (Civitas), 2005, pp. 627-663.

MARINUCCI, G., Il reato come azione. Critica di un dogma, $1^{\text {a }}$ ed., Milano (Giuffrè), 1971.

MIR PUIG, S., Derecho penal. Parte general, 10ª ed., Barcelona (Reppertor), 2015.

MOORE, M., Causation and Responsibility. An essay in Law, Morals, and Metaphysics, $1^{\text {a }}$ ed., Oxford (Oxford University Press), 2009.

MUÑOZ CONDE, F.; GARCÍA ARÁN, M., Derecho penal. Parte general, $9^{\mathrm{a}}$ ed., Valencia (Tirant lo Blanch), 2015.

MORENO CATENA, V.; CORTÉS DOMÍNGUEZ, V., Derecho procesal penal, $8^{\mathrm{a}}$ ed., Valencia (Tirant lo Blanch), 2017.

OLMEDO CARDENETE, M., La inducción como forma de participación accesoria, $1^{\text {a }}$ ed., Madrid (Edersa Instituto de Criminología), 1999.

PARLATO, L., «Concussione/induzione: i punti deboli dell'accertamento processuale», en Riformulazione-frattura del delitto di concussione ex art. 317 c.p., ponencia pronunciada en el marco del workshop en la Università degli Studi di Milano-Bicocca. Disponible en $<$ https://www.penalecontemporaneo.it/d/3134riformulazione-frattura-del-delitto-di-concussione-ex-art-317-cp $>$ [Consultado el 16/09/2019].

PELISSERO M., «Reati omissivi», en GROSSO, C. F.; PELISSERO, M.; PETRINI, D.; PISA, P., Manuale di diritto penale. Parte generale, $2^{\mathrm{a}}$ ed., Milano (Giuffrè), 2017, pp. 205-226.

PEÑARANDA RAMOS, E., La participación en el delito y el principio de accesoriedad, $1^{\text {a }}$ ed., Madrid (Tecnos), 1990.

PEÑARANDA RAMOS, E., «Homicidio», en BAJO FERNÁNDEZ, M., Compendio de derecho penal. Parte especial, vol. I, $1^{\text {a }}$ ed, Madrid (Centro de Estudios Ramón Areces), 2003, pp. 21-174.

PEÑARANDA RAMOS, E., «Sobre la responsabilidad en comisión por omisión respecto de hecho delictivos cometidos en la empresa (y en otras organizaciones)», en Derecho y justicia penal en el siglo XXI. Liber amicorum en homenaje al profesor Antonio González-Cuéllar García, $1^{\mathrm{a}}$ ed., Madrid (Editorial Colex), 2006, pp. 411-430. 
PEÑARANDA RAMOS, E., «La tipicidad en los delitos omisivos», en Memento práctico Francis Lefebvre. Penal 2019, $1^{\mathrm{a}}$ ed., Madrid (Francis Lefebvre), 2018, pp. 177-191.

PÉREZ MANZANO, M., Autoría y participación imprudente en el Código penal del 1995, 1ª ed., Madrid (Civitas), 1999.

PÉREZ MANZANO, M.; CANCIO MELIÁ, M., «Principios del derecho penal (III)», en LASCURAÍN SÁNCHEZ, J. A., Manual de Introducción al Derecho Penal, $1^{a}$ ed., Madrid (Agencia Estatal Boletín oficial del Estado), 2019, pp. 91-116.

PULITANÒ, D., Diritto penale, 8ª ed., Torino (Giappichelli), 2019.

RISICATO, L., Combinazione e interferenza di forme di manifestazione del reato, Milano (Giuffrè), 2001.

ROBLES PLANAS, R., «Participación en el delito de imprudencia», $R D P C$, núm. 6, 2000, pp. 223-251.

ROBLES PLANAS, R., Garantes y cómplices. La intervención por omisión y en los delitos especiales, $1^{\text {a }}$ ed., Barcelona (Atelier), 2007.

ROCA DE AGAPITO, L., Las acciones cotidianas como problema de la participación criminal, $1^{\text {a }}$ ed., Valencia (Tirant lo Blanch), 2013.

RODRÍGUEZ MOURULLO, G., Derecho penal: parte general, $1^{\mathrm{a}}$ ed., Madrid (Civitas), 1978.

ROXIN, C., Autoría y dominio del hecho en derecho penal, $1^{\text {a }}$ ed., Madrid (Marcial Pons), 1998.

ROXIN, C., Derecho penal. Parte general. Tomo II. Especiales formas de aparición de delito, $1^{\text {a }}$ ed., Madrid (Civitas), 2014.

RUEDA MARTÍN, M. A., ¿Participación por omisión? Un estudio sobre la cooperación por omisión en un delito de acción doloso cometido por un autor principal, $1^{\text {a }}$ ed., Barcelona (Atelier), 2013.

SÁNCHEZ-VERA GÓMEZ-TRELLES, J., «Intervención omisiva, posición de garante y prohibición de sobrevaloración del aporte», ADPCP, 1995, pp. 187-263.

SÁNCHEZ-VERA GÓMEZ-TRELLES, J., «Caso Vinader», en Casos que hicieron doctrina en derecho penal, $2^{\mathrm{a}}$ ed., Madrid (La Ley), 2011, pp. 259-275.

SÁNCHEZ-VERA GÓMEZ-TRELLES, J., «En los límites de la inducción», InDret, núm. 2, 2012, pp. 1-42. 
SCHÜNEMANN, B., Fundamento y límites de los delitos de omisión impropia, $1^{\text {a }}$ ed., Madrid (Marcial Pons), 2009.

SGUBBI, F., Responsabilitá penale per omesso impedimento dell'evento, $1^{\text {a }}$ ed., Padova (Cedam), 1975.

SILVA SÁNCHEZ, J. M., El delito de omisión. Concepto y sistema, $1^{\text {a }}$ ed., Barcelona (Librería Bosch), 1986.

SILVA SÁNCHEZ, J. M., «Aspectos de la comisión por omisión: fundamento y formas de intervención. El ejemplo del funcionario penitenciario», Cuadernos de política criminal, 1989, pp. 367-404.

SILVA SÁNCHEZ, J. M., «Apuntes sobre el contexto histórico-dogmático del artículo 11 del código penal», La Ley, núm. 5, 1996, pp. 1557-1564.

SILVA SÁNCHEZ, J. M., El nuevo Código penal: cinco cuestiones fundamentales, $1^{\text {a }}$ ed., Barcelona (José María Bosch Editor), 1997.

SILVA SÁNCHEZ, J. M., «Criterios de asignación de responsabilidad en estructuras jerárquicas», Cuadernos de derecho judicial, vol. II, 1997, pp. 9-58.

SILVA SÁNCHEZ, J. M., «Entre la omisión de socorro y la comisión por omisión. Las estructuras de los arts. 195.3 y 196 del Código penal», en Problemas especificos de la aplicación del Código Penal, Madrid (Consejo General del Poder Judicial), 1999, pp. 153-172.

TOMÁS-VALIENTE LANUZA, C, «Artículo 11», en GÓMEZ-TOMILLO, M., Comentarios prácticos al Código penal. Parte general, t. I, Cizur Menor (Thomson Reuters Aranzadi), 2015.

VIVES ANTÓN, T. S., «Artículo 11. Introducción», en Comentarios al código penal del 1995, $1^{\text {a }}$ ed., Valencia (Tirant lo Blanch), 1996. 